\title{
Dense housing and urban sustainable development
}

B. $\mathrm{Su}$

School of Architecture, Unitec Institute of Technology, New Zealand

\begin{abstract}
There are close relationships between urban housing density and urban sustainability. It is important but difficult to accurately estimate the appropriate housing density to enable a city to meet variable future social, economic and environmental needs. If a city's urban housing density could be adjusted or influenced through some "regulators" - some design factors, housing developments could be guided along the right path to meet such needs. This study randomly selected 40 existing housing projects built during the decade 1995 to 2004 through which to investigate the interactive relationships between the various design data of these housing projects and to try to identify the design factors which could be applied through housing policies to impact housing density in the local housing market for future dense housing development engaged with future urban sustainability.
\end{abstract}

Keywords: dense housing development, house, housing density, house design, urban sustainable development.

\section{Introduction}

Dense housing is becoming a common solution for meeting the growth of urban populations and economies, as well as limiting urban sprawl. Policies which foster higher density housing developments related to urban sustainability are similar in the United Kingdom, Australia and New Zealand. Medium density housing is already a common form of urban housing in Australia. The literature in Australia documents the evolution of the typology in detail and presents a case for medium density housing as a solution to urban housing in general [1]. Literature on case studies within the density range from $20 \mathrm{dph}$ to $83 \mathrm{dph}$ (dwellings per hectare) extends the relevant design area to include issues related 
to the environment, sustainability and community attitude, and detail design issues such as urban planning, neighborhood design, pedestrian, vehicular, parking, identity, privacy, security, layout, climate, energy efficiency, market [2], children, site planning and landscaping [3,4]. The literature comprehensively summarizes good dense housing layout planning principles with sustainable urban design [5]. There is some literature on local medium and higher density housing development and urban sustainability related to urban centers in New South Wales [6-9]. AMCORD - a national mode code for residential development [10], ResCode - a local government code and Melbourne 2030 - local government strategy [11, 12] regulate and foster new medium density housing design and development. The Australian experience is directly relevant to New Zealand, though it requires conversion of building systems and design traditions, and is based on a more prescriptive regulatory system.

The United Kingdom has a longer history of developing dense housing. Housing density between 25 and 30dph in the private sector in suburban areas is common and generally higher than in New Zealand. In England from 1993 to 2001, the density of newly built dwellings remained fairly constant at an average of $25 \mathrm{dph}$. In 2006 however, it increased to $40 \mathrm{dph}$. For London, new dwelling density rose from 48dph in 1993 to 84dph in 2006 [13]. Housing development is operated in a highly regulated environment with a good foundation of housing policy and urban planning [14]. Some comprehensive publications on medium and high density housing, founded on experience in practice, include: summaries of design advances in international housing during the twentieth century and the determining factors in the development of urban quality; how the various policy instruments available to public authorities can be used in a positive manner to deliver higher quality residential developments [15]; the most significant schemes built in Britain during the century as a resource for practitioners in creating future high quality housing [16]; good design through alternative layout and house type in an environment where the housing policies foster higher residential density to improve development margin, market value and urban living environment [17]. The British experiences in practice have relevance to New Zealand housing development if adapted for local social, economic and environmental conditions. There is neither a universal definition nor description of housing density nor a universal threshold or band to define low, medium and high density housing for different countries or for different cities in a country. There are however different ways to define urban housing as follows:

- $\quad$ Residential density (site density) - the number of dwellings per hectare of the site area;

- $\quad$ Net density (net residential density) - residential density for the site area within the territorial boundary of housing ownership;

- Gross density (neighborhood density) - residential density for the land area including the site area within the territorial boundary of housing ownership and associated areas;

- $\quad$ Population density - the number of people in any given area;

- $\quad$ Floor area ratio - the total floor area of buildings to the site area. 
The AMCORD encourages the use of site density, net residential density, neighborhood density and urban centre dwelling density for measuring urban housing density. Auckland, Wellington and Christchurch city councils and Housing New Zealand Corporation use net density to define the density band of medium density housing. Within this band, the average site area per dwelling is $150 \mathrm{~m}^{2} /$ dwelling to $350 \mathrm{~m}^{2} /$ dwelling (or the number of dwellings per hectare site area is 29 to 66 dwellings). Low or high density housing is lower or higher than this band. Waitakere City Council applies an effects-based process to decisionmaking on medium density housing proposals. The Auckland Regional Council identifies "residential intensification as developments with a net site density of $500 \mathrm{~m}^{2}$ or less", medium density at $350 \mathrm{~m}^{2}$ or less, and higher density at $200 \mathrm{~m}^{2}$ or less net site density. Projected population increase for Auckland is over 200,000 by 2050 , whereas under previous zoning rules in the existing District Plan there was only capacity for approximately 30,000 additional people. The Auckland City Council has concluded that Auckland city, due to its location in the middle of urban Auckland, with no rural land to expand into, needs to cater for this additional population growth through intensification of housing density $[18,19]$. The Strategic Growth Management Areas [20] in the Auckland region have been identified by urban planners for new infill homes to cater for population growth over the next 50 years. In the future, more medium or high density housing will be built in the existing Auckland region and dense housing will become increasingly important for urban sustainability. This study randomly selected 40 existing medium and high density housing projects in the Auckland region, built during the decade from 1995 to 2004 . Housing types in the 40 housing projects include two and three storey detached, semi-detached and attached medium and higher density dwellings. Detached dwellings are stand-alone townhouses with a smaller distance between them than low density houses. Attached dwellings are terraced town houses. Semi-detached dwellings include a pair of townhouses sharing one wall or townhouses sharing only the party wall between garages. Most projects contain more than one housing type. Table 1 shows ranges of design data for the 40 housing projects. The design data for individual housing projects in this study are from the calculation and measurement of site plans and building plans. This study investigates the interactive relationships between site area, average site area per dwelling, ratio of footprint to site, average outdoor space per dwelling, dwellings per hectare, floor area ratio (FAR), average floor

Table 1: $\quad$ Design data range of sample housing projects.

\begin{tabular}{|c|c|c|}
\hline Site areas & Number of dwellings & $\begin{array}{c}\text { Average floor area per } \\
\text { dwelling }\end{array}$ \\
\hline $2204-24728 \mathrm{~m}^{2}$ & $13-113$ & $59-195 \mathrm{~m}^{2}$ \\
\hline Dwellings per hectare & Average site area per dwelling & Floor area ratio (FAR) \\
\hline $29-125 \mathrm{dph}$ & $80-341 \mathrm{~m}^{2}$ & $0.28-1.32$ \\
\hline Ratio of footprint to site area & $\begin{array}{c}\text { Average outdoor space per } \\
\text { dwelling }\end{array}$ & $\begin{array}{c}\text { Parking ratio (internal \& } \\
\text { external) }\end{array}$ \\
\hline $0.14-0.57$ & $35-250 \mathrm{~m}^{2}$ & $1-4$ \\
\hline Indoor parking ratio & Outdoor parking ratio & Building height \\
\hline $0-2$ & $0-2$ & $2-3$ storey \\
\hline
\end{tabular}


area per dwelling, parking ratios and building height to identify the design factors, which can be applied to impact on housing density in the local market.

\section{Data analysis}

\subsection{Housing density}

This study investigates the positive and negative impacts of increasing housing density according to the design data of the 40 housing projects shown in Figures 1-9. An increase in housing density is associated with an increasing trend in building floor area ratios and a decreasing trend in average floor area per dwelling (Figures 1 and 2). Increasing housing density can supply more dwellings and living spaces for more occupants within a given area of land, but decreasing living space per dwelling could degrade living conditions. Increasing housing density can decrease average site area per dwelling (Figure 3) to save urban land and limit urban sprawl, but decreasing average outdoor space per dwelling (Figure 4) such as reducing outdoor parking ratio (Figure 5), and increasing building height (Figure 6), could degrade the living environment. Increasing housing density is associated with a decreasing trend in outdoor parking ratios and total parking ratios (Figure 7), and an increasing trend in indoor parking ratios (Figure 8) and building heights. An increasing trend in site footprint associated with housing density (Figure 9) increases impermeable hard surface and decreases the passage of rainwater through soil to reach ground water, which increases the runoff volume of rainwater and increases pressure on the existing drainage system designed for normal density. Decreasing outdoor and total parking ratios could cause parking problems at dense housing sites and become a contentious issue with local residents if current public transportation is not efficient and car dependence does not decrease. Increasing building heights and decreasing average outdoor space per dwelling can negatively impact on aspects of living environment such as privacy, noise, sun, etc unless careful, skilled design is ensured. A housing density of $30 \mathrm{dph}$ is identified as the threshold [17], above which high design standards become increasingly critical the more densities rise. Standard design and standard layouts will not work on high-density developments. Increases in housing density must engage with good design quality to minimize negative impact.

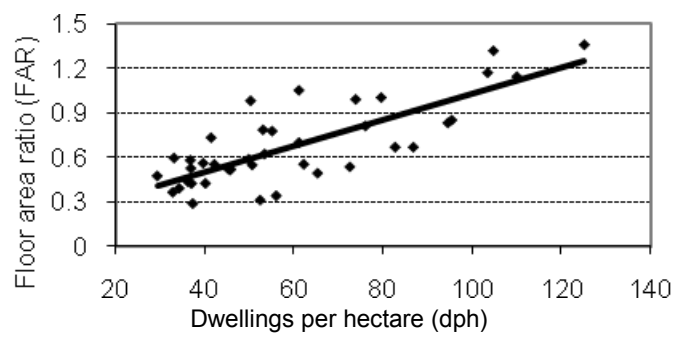

Figure 1: Floor area ratio and housing density. 


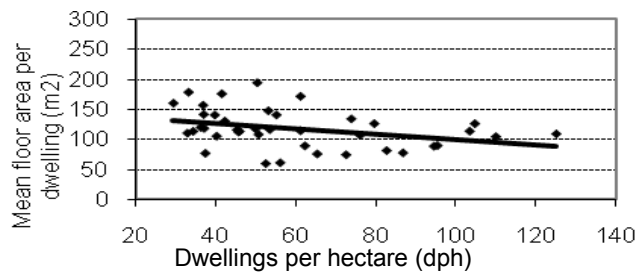

Figure 2: Average floor area per dwelling and housing density.

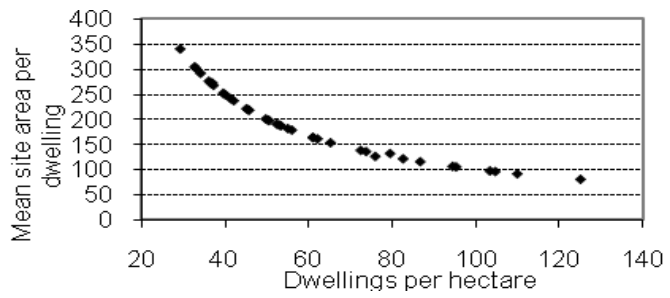

Figure 3: $\quad$ Site area per dwelling and housing density.

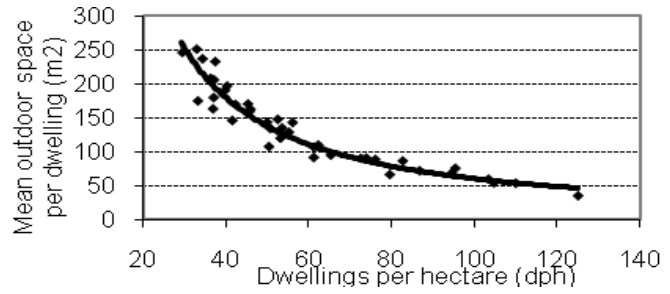

Figure 4: $\quad$ Outdoor space per dwelling and housing density.

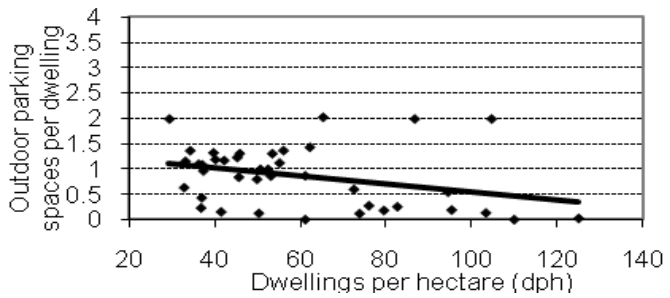

Figure 5: Outdoor parking ratio and housing density.

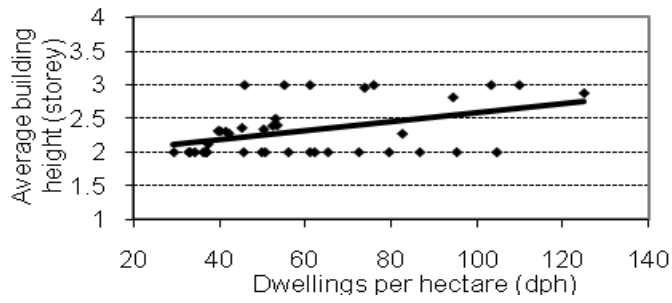

Figure 6: Average building height and housing density. 


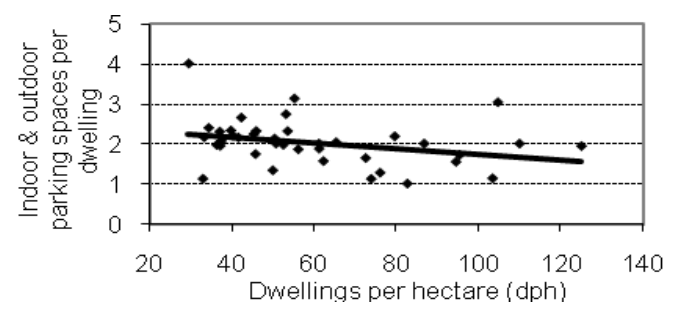

Figure 7: Indoor and outdoor parking ratio and housing density.

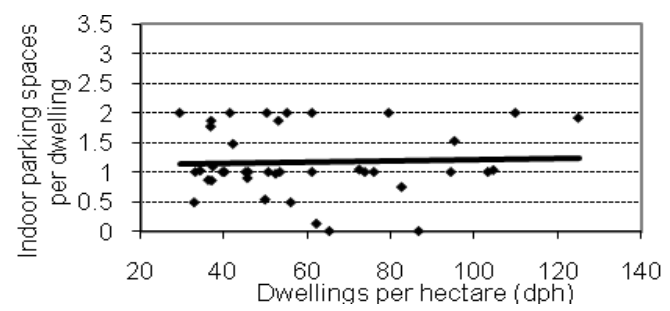

Figure 8: Indoor parking ratio and housing density.

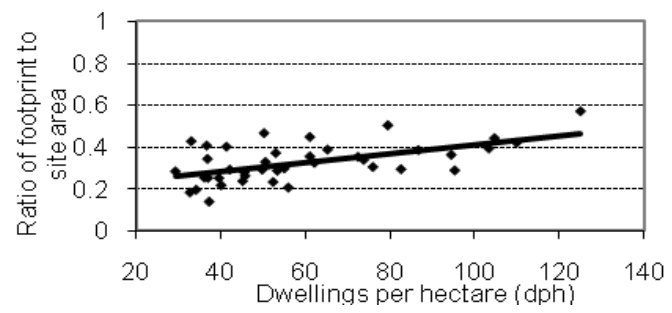

Figure 9: $\quad$ Ratio of footprint to site and housing density.

\subsection{Site area}

There are many constraints that impact on the supply of new housing. Basic requirements are suitable land, labour (designer, engineer, builder, services, etc) and materials. Compulsory consents and approvals are resource consent, building consent, Transit approval etc prior to development. Costs such as those for land, construction, material, finance, tax, etc. need to be within a range which will allow a reasonable return to developers, though developers respond not only to market forces: prices, costs and profit of development, but also to land availability and regulation. Land availability and land ownership are both regarded as major constraining factors for new housing development in Auckland. Land supply issues are considered to affect both infill development and Greenfield development [19]. Figures 10-19 show how design data varies according to increases in site area for the 40 sample housing projects. An increase in the site areas is associated with a decreasing trend in housing density (Figures 10 and 11). The data show that a large building site for dense housing 


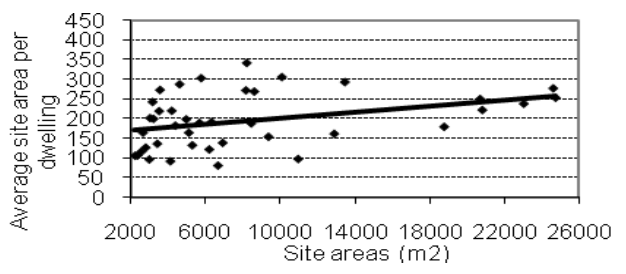

Figure 10: Average site area per dwelling and site area.

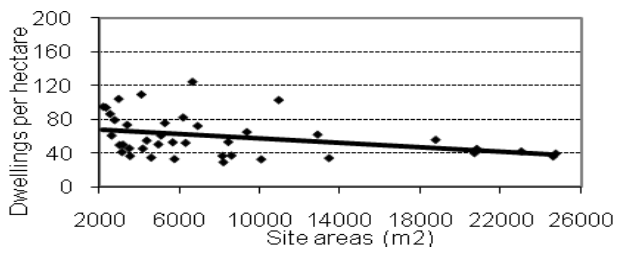

Figure 11: Dwellings per hectare and site area.

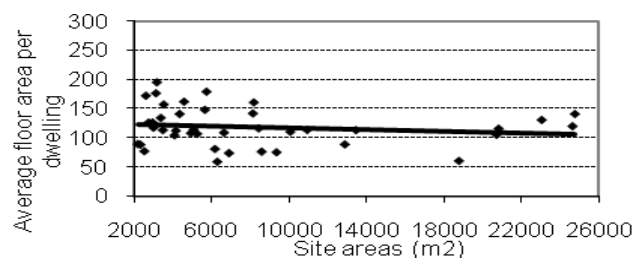

Figure 12: $\quad$ Average floor area per dwelling and site area.

development is more likely to encourage or result in a relatively low housing density. If a certain amount of land is available on the market for dense housing development during a certain period of time e.g. ten years, to supply a large number of small parcels could encourage relatively higher housing density than a small number of large parcels or vice versa which are regulated by land issue policy or related consents. If controlling land size through land issue policy or related consents could be applied as one of the factors to influence housing density on the market for a certain period of time in the future, housing density could be regulated to engage with future urban sustainability.

Decreasing trends in average floor area per dwelling (Figure 12), ratio of footprint to site area (Figure 13), building height (Figure 14) indoor parking ratio (Figure 15), and increasing trends in average outdoor space per dwelling (Figure 16), average outdoor space per dwelling (Figure 17) and total parking ratio (Figure 18) associated with an increase of site area, are similar to the data associated with a decrease in housing density in Figures 2 and 4-9. Those relationships also support the contention that land issue policy and consents could be applied not only to impact on housing density but also on indoor living conditions such as internal living space, and aspects of the living environment such as outdoor space, parking, etc. 


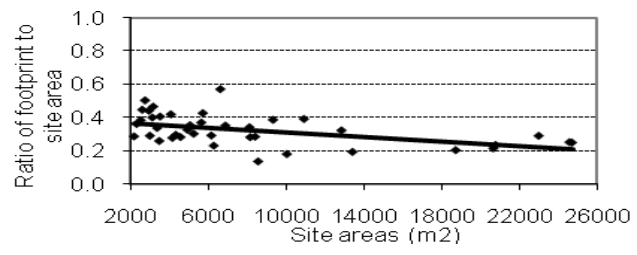

Figure 13: Ratio of footprint to site area and site area.

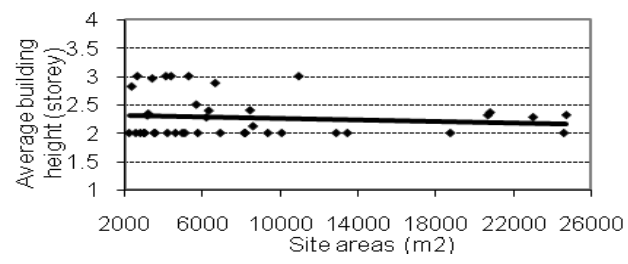

Figure 14: Average building height and site area.

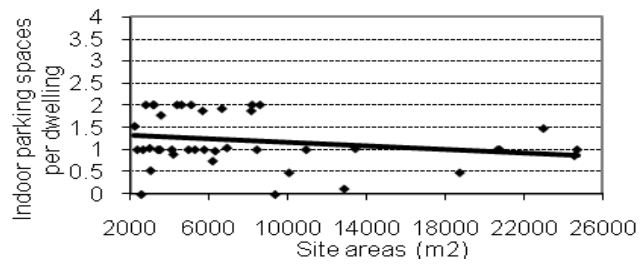

Figure 15: Indoor parking ratio and site area.

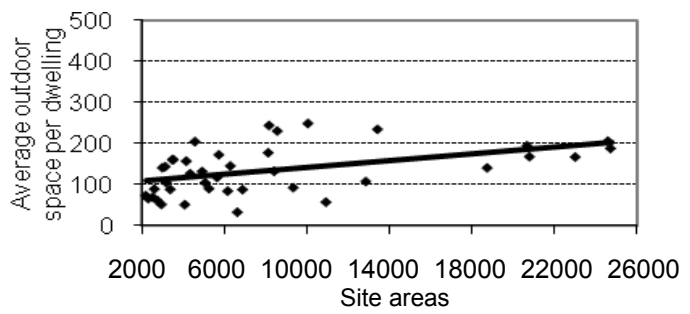

Figure 16: Outdoor parking ratio and site area.

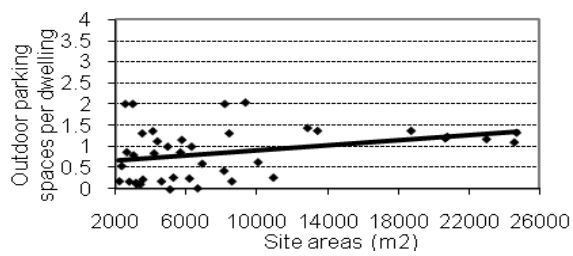

Figure 17: Outdoor parking ratio and site area. 


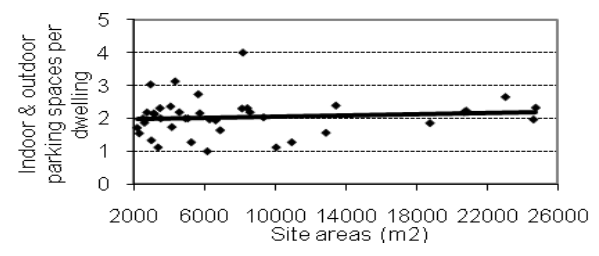

Figure 18: Indoor and outdoor parking ratio and site area.

\subsection{Average floor area per dwelling}

In the Auckland region, the proportion of building consented multi-dwellings (units, apartment, terraced housing, etc) to total building consented dwellings rose from $25 \%$ in 1991 to over 50\% in 2004 (Figure 19). The average floor area of consented standalone houses increased dramatically from $140 \mathrm{~m}^{2}$ in 1991 to $210 \mathrm{~m}^{2}$ by the end of 2004. Meanwhile, the average floor area of consented multi-dwelling housing has generally fallen to under $100 \mathrm{~m}^{2}$. From 1995 to 2004 , average floor area of multidwelling housing has steadily decreased from $140 \mathrm{~m}^{2}$ in 1995 to $100 \mathrm{~m}^{2}$ in 2004 (Figure 20). Building consents related to multi-dwelling housing could be influenced by intensification policy in the Auckland region. Figures 21 and 22 show variations in housing density associated with an increase in average floor area per dwelling for the 40 housing projects from 1995 to 2004. An increase in average floor area per dwelling is associated with a decreasing trend in housing density (Figures 21 and 22).

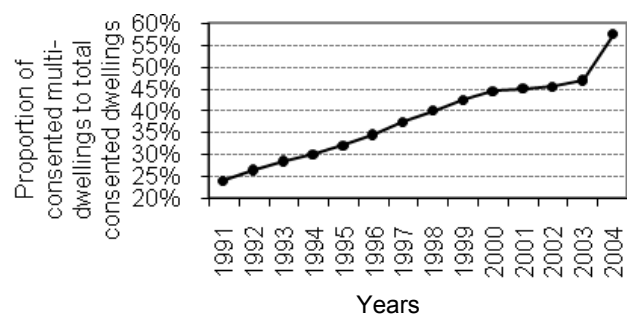

Figure 19: Building consents for multi-dwellings in Auckland region (data source: Auckland regional council).

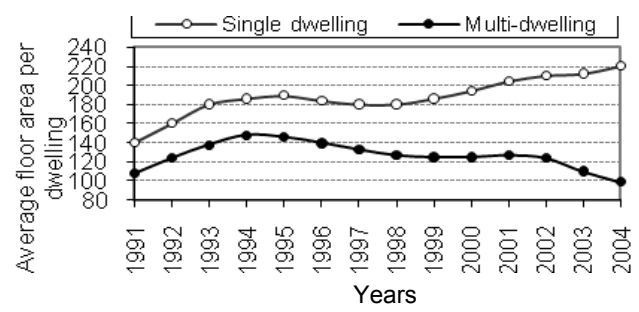

Figure 20: Average floor area of housing consents from 1991 to 2004 in Auckland (data source: Auckland regional council). 


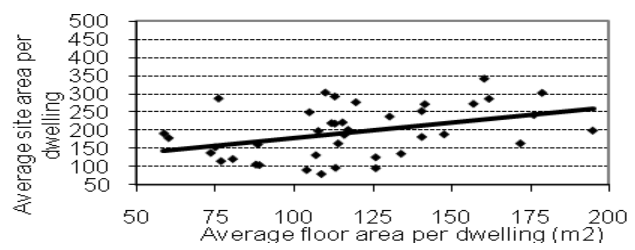

Figure 21: Average site area per dwelling and average floor area per dwelling.

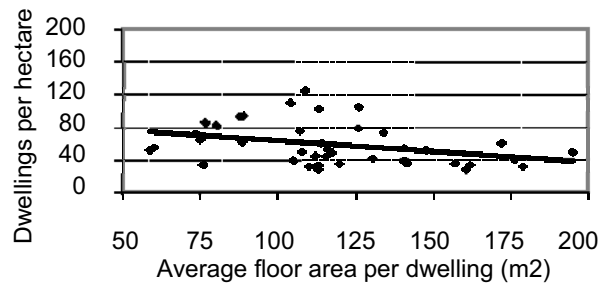

Figure 22: Dwellings per hectare and average floor area per dwelling.

If the average floor area per dwelling at a particular site could be regulated through related building consents, when building height is limited according to the different residential zones, a larger average floor area per dwelling could result in fewer dwellings built. Likewise, a relatively lower housing density or a smaller average floor area per dwelling could result in a higher number of dwellings built at the site and a relatively higher housing density. Table 2 shows height limitations and densities for different residential zones in the Auckland region.

Table 2: Building height and density for different residential zones in Auckland (Source: Auckland city district plan: isthmus section).

\begin{tabular}{|c|c|}
\hline Zone & Maximum height \\
\hline Residential 1 & $8 \mathrm{~m}$ (2 storey) \\
\hline Residential 2b & $8 \mathrm{~m}$ (2 storey) \\
\hline Residential 5 & $8 \mathrm{~m}$ (2 storey) \\
\hline Residential 6a & $8 \mathrm{~m}$ (2 storey) \\
\hline Residential 6b & $10 \mathrm{~m}$ (2-3 storey) \\
\hline Residential 7a & $10 \mathrm{~m}$ (2-3 storey) \\
\hline Residential 7b & $12.5 \mathrm{~m}$ (3-4 storey) \\
\hline Residential 8a & $11 \mathrm{~m}$ (2-3 storey) \\
\hline Residential 8b & $14 \mathrm{~m}$ (3-4 storey) \\
\hline
\end{tabular}

\section{Conclusions}

An increase in local urban housing density is inevitable for future urban sustainability because of continued growth in the urban population and limited sources of urban land. Government urban growth strategies and policies also foster dense housing developments. Dense housing is becoming a common solution for sustainable urban development. Without skilled and careful design, increasing housing density at a particular site could create negative impacts on 
living conditions and living environment when compared with low density housing. What urban planners and architects can do is to provide higher standards of design to minimize the negative impacts of increasing housing density. There are good international precedents, relevant to dense housing, which can be applied to local dense housing design if adapted for local conditions.

It is important, though difficult, to accurately estimate the appropriate housing density a city needs to achieve future sustainable urban development. However, determining how to guide or adjust housing density on the right path to meet and balance variable future social, economic and environmental requirements is both more important and more practicable. Social, economic and environmental requirements affect the housing density of a city to different degrees and sometimes in opposing directions simultaneously. It is difficult to identify a simple relationship between housing density and any one of these major factors, but their influences still remain in developed housing projects. Existing dense housing projects can be used to explore the interactive relationships among various aspects of their design data. The relationships may be used as the "regulators" to guide local dense housing developments on the path of sustainable urban development. This study finds that land issue policy to control the average size of land parcels for dense housing development in urban areas could also be applied as a regulator to impact on urban housing density if a certain amount of land is available for the local housing market within a certain period of time; building consent policy to control the average floor area of a building site could be applied as a regulator to impact the on housing density at the site.

\section{References}

[1] Judd, B. and Dean, J. (ed.) (1983). Medium Density Housing in Australia. Canberra: RAIA Education Division.

[2] Judd, B. (1993). Design for Urban Living: Recent Medium Density Group Housing in Australia. Canberra: The Royal Australian Institute of Architects

[3] Marcus, C. C. and Sarkissian, W. (1983). The Medium-Density Housing Kit. Milsons Point, N.S.W.: Social Impacts Publications.

[4] Marcus, C. C. and Sarkissian, W. (1986). Housing as If People Mattered. Berkeley: University of California Press.

[5] King, S., Rudder, D. and Ballinger, J. (1996). Site Planning in Australia. Sydney: Australia Government Publishing Service.

[6] New South Wales Urban Design Advisory Service (1998). Better Urban Living, Guidelines for Urban Housing in NSW. Sydney: Department of Urban Affairs and Planning.

[7] New South Wales Urban Design Advisory Service (1998). Residential Densities. Sydney: New South Wales Department of Urban Affairs and Planning. 
[8] New South Wales Urban Design Advisory Service (2001). The Residential Flat Design Patten Book. Sydney: New South Wales Department of Urban Affairs and Planning.,

[9] New South Wales Urban Design Advisory Service (2002). Residential Flat Design Code. Sydney: New South Wales Department of Urban Affairs and Planning.

[10] Commonwealth Department of Housing and Regional Development (1995). Australia Model Code for Residential development. Canberra: Australia Government Publishing Service.

[11] Department of Sustainability and Environment (2001). ResCode. Melbourne: State Government Victory.

[12] Department of Sustainability and Environment (2002). Melbourne 2030. Melbourne: State Government Victory.

[13] Department for Environment, Food and Rural Affairs (2007). Sustainable Development Indicators in Your Pocket 2007. London: Defra Publications.

[14] Balchin, P. and Rhoden, M. (2002). Housing Policy - An Introduction 4th edition. London and New York: Routledge.

[15] Carmona, M. (2001). Housing Design Quality: Through policy, Guidance and Review. London and New York: Spone Press.

[16] Colquhoun, I. (1999). RIBA Book of 20th Century British Housing. Oxford: Butterworth-Heinemann.

[17] Commission for Architecture and the Built Environment (2003). The Value of Housing Design and Layout. London: Thomas Telford.

[18] ACC. (2003). Auckland City District Plan: Plan Change 58. Auckland: Auckland City Council.

[19] Centre for Housing Research, Aotearoa New Zealand (2007). Housing Supply in the Auckland Region 2000 - 2005. Wellington: Housing New Zealand Corporation.

[20] ACC. (2001). The Residential Design Guide for Developments in Residential Zones in Strategic Growth Management Areas. Auckland: Auckland City Council. 